\title{
Nicotinic Acetylcholine Receptors and Modulation of Learning in 4- and 27-Month-Old Rabbits
}

\author{
Jian-Guo Li', Melissa Lehr' ${ }^{2}$, Lee-Yuan Liu-Chen' and Diana S Woodruff-Pak ${ }^{2}$ \\ 'Department of Pharmacology, Temple University School of Medicine, Philadelphia, PA, USA; ${ }^{2}$ Department of Psychology, Temple University, \\ Philadelphia, PA, USA
}

\begin{abstract}
Using drugs acting on nicotinic acetylcholine receptors (nAChRs), we examined temporal-parietal and frontal cortex, hippocampus, and cerebellum to identify sites of cognition enhancement in 4- and 27-month rabbits. First, we compared radioligand receptor binding for neuronal $\alpha \beta$ heteromeric nAChRs $\left(\left[{ }^{3} \mathrm{H}\right]\right.$ epibatidine) and $\alpha 7$ homomeric $n A C h R s\left(\left[{ }^{3} \mathrm{H}\right]\right.$ methyllycaconitine) in rabbits and rats. In cerebellum, nAChR levels of both species are low, about at the detection limit of the radioligand binding assays. Next, we compared nAChRs in 4- and 27-month vehicle-treated rabbits trained in delay eyeblink conditioning. Older rabbits conditioned more poorly and had lower $\alpha \beta$ heteromeric $\mathrm{nAChR}$ binding in hippocampus than young rabbits. For cognition enhancement, galantamine (mild cholinesterase inhibitor and allosteric modulator of nAChRs) or MEM-3389 ( $\alpha$ 7nAChR agonist formerly identified as AR-R I7779) was injected before conditioning. Drugs improved learning in both age groups. In 27-month rabbits, drugs increased expression of frontal and temporal-parietal $\alpha \beta$ heteromeric nAChRs and hippocampal $\alpha \beta$ and $\alpha 7 \mathrm{nAChRs.} \mathrm{In} \mathrm{4-month} \mathrm{rabbits,} \mathrm{drugs} \mathrm{increased} \mathrm{expression} \mathrm{of} \alpha 7$ homomeric $n A C h R s$ in frontal and temporal-parietal cortex and hippocampus, but increased expression of $\alpha \beta$ heteromeric nAChRs only occurred in temporal-parietal cortex. Increased expression of $\alpha \beta \mathrm{nAChRs}$ was more extensive in older drug-treated rabbits, whereas increased expression of $\alpha 7 \mathrm{nAChRs}$ was more prevalent in younger drug-treated rabbits, suggesting different substrates for amelioration (27-month rabbits) vs facilitation (4-month rabbits) of learning. Results provide evidence for cortical as well as hippocampal nAChR modulation of delay eyeblink conditioning and demonstrate that more sensitive binding assays are required to assess $\mathrm{nAChR}$ effects in cerebellum.
\end{abstract}

Neuropsychopharmacology (2008) 33, 2820-2830; doi: I0.1038/npp.2008. I; published online 6 February 2008

Keywords: aging; cerebellum; eyeblink classical conditioning; frontal and temporal-parietal cortex; hippocampus; radioligand binding

\section{INTRODUCTION}

Nicotinic acetylcholine receptors (nAChRs) play a significant role in learning and memory (Changeux et al, 1998). During normal aging, there is a reduction in some nAChR subunits (eg, Court et al, 1997). A form of learning that has age-associated deficits and activates nAChRs is eyeblink classical conditioning (Woodruff-Pak et al, 2001). Eyeblink conditioning reveals age-related deficits in all mammalian species that have been tested, including humans. Moreover, delay eyeblink conditioning is impaired profoundly in patients with AD (Solomon et al, 1991; Woodruff-Pak et al, 1990), making the paradigm relevant for preclinical studies of cognition-enhancing drugs. In addition to parallels with human behavior and neurobiology, the model system of eyeblink classical conditioning possesses a considerable advantage over the behavioral models commonly used

Correspondence: Professor DS Woodruff-Pak, Department of Psychology, Temple University, I70I North 13th Street, Philadelphia, PA 19122, USA, Tel: + I 215204 1258, Fax: + | 2152045539 ,

E-mail: pak@temple.edu

Received 16 August 2007; revised 5 December 2007; accepted 21 December 2007 preclinically: the essential neural circuitry in the cerebellum has been identified (Christian and Thompson, 2003) along with circuits in hippocampus and cortex (Weible et al, 2007). On the basis of the documented neural circuitry for eyeblink conditioning, we focused on nAChR binding in frontal and temporal-parietal cortex, hippocampus, and cerebellum.

Much of the research on the neurobiology of classical conditioning and aging has been carried out in rabbits, yet the effects of aging on nAChRs in rabbits have not been reported in the literature. Central nervous system nAChRs are composed of five subunits (called $\alpha$ and $\beta$ subunits) arranged around a ligand-gated excitatory ion channel. The two main categories of neuronal nAChRs are heteropentamers, constructed from combinations of $\alpha$ - and $\beta$-subunits (Conroy et al, 1992), and homopentamers, constructed from one subunit type, $\alpha 7$ in mammals (Couturier et al, 1990; Schoepfer et al, 1990). The most abundant nAChR subtypes in the brain appear to be: (a) those that participate in highaffinity agonist binding associated with $\alpha 4$ and $\beta 2$ subunits and (b) those sensitive to blockade by $\alpha$-bungarotoxin and containing $\alpha 7$ subunits. It is these two nAChR subtypes that are the focus of our investigation. 
During normal aging, there is a diminution in the expression of high-affinity binding associated with $\alpha \beta$ heterodimers that has been reported in human (eg, Giacobini, 1992) and in rodent brain (Araujo et al, 1990; Zhang et al, 1990). In human brains, there are age-related declines in $\alpha 7$ homomeric nAChRs in the entorhinal cortex and thalamus, but the levels in the hippocampus (Court et al, 1997), frontal cortex, and cerebellum (Falk et al, 2003) remain stable. Comparisons of CBA and C57BL/6 mice revealed that loss of $\alpha 7$ homomeric nAChRs in the hippocampus is strain dependent (Gahring et al, 2005).

A role for acetylcholine in the model system of eyeblink conditioning has been demonstrated. We focused on nAChRs because of their loss in normal aging and tested cognition-enhancing drugs targeting nAChRs. AR-R-17779 (now called MEM-3389) is an agonist shown to be selective for $\alpha 7 \mathrm{nAChRs}$ in frog oocytes (Papke et al, 2004). MEM-3389 had not been tested in eyeblink conditioning in rabbits, making it necessary for us to carry out doseresponse testing. We anticipated that MEM-3389 would have efficacy in this model as a partial $\alpha 7$ agonist improved eyeblink conditioning in older rabbits (Woodruff-Pak et al, 1994). Galantamine is among the most effective cognition enhancers tested in the eyeblink classical conditioning model (Weible et al, 2004; Simon et al, 2004; Woodruff-Pak et al, 2001, 2003). Galantamine has mechanisms of action that include both mild acetylcholinesterase inhibition and allosteric potentiating effects at nAChRs (Popa et al, 2006). A dose-response study on the effects of galantamine in eyeblink conditioning indicated that $3.0 \mathrm{mg} / \mathrm{kg}$ facilitated learning (Woodruff-Pak and Santos, 2000).

The initial step in this project was to identify dose(s) of MEM-3389, an agonist selective for $\alpha 7 n A C h R s$, which enhanced acquisition of conditioned eyeblink responses. Using this dose of MEM-3389 (1.0 mg/kg), $3.0 \mathrm{mg} / \mathrm{kg}$ galantamine, and vehicle and radioligand receptor binding assays for neuronal $\alpha \beta$ heteromeric nAChRs $\left(\left[{ }^{3} \mathrm{H}\right]\right.$ epibatidine $\left(\left[{ }^{3} \mathrm{H}\right]\right.$ Epi $\left.)\right)$ and $\alpha 7$ homomeric nAChRs $\left(\left[{ }^{3} \mathrm{H}\right]\right.$ methyllycaconitine $\left.\left(\left[{ }^{3} \mathrm{H}\right] \mathrm{MLA}\right)\right)$, we aimed to: (a) determine binding affinity and levels of $\alpha \beta$ heteromeric and $\alpha 7$ homomeric nAChRs in four brain regions in young vehicle-treated rabbits and compare them to $\mathrm{nAChR}$ subunits at these brain sites in young rats; (b) compare binding affinity and levels of $\alpha \beta$ heteromeric and $\alpha 7$ homomeric nAChRs in four brain regions in 4- and 27-month-old vehicle-treated rabbits; and (c) evaluate the effects of MEM-3389 and galantamine on learning and on binding affinity and levels of $\alpha \beta$ heteromeric and $\alpha 7$ homomeric nAChRs in brain sites of demonstrated involvement in eyeblink conditioning in 4- and 27-month-old rabbits. Our ultimate goal was to identify sites of action of cognition-enhancing drugs.

\section{MATERIALS AND METHODS}

\section{Study Population}

Rats. Tissue from a total of 12 male Sprague-Dawley rats was used for initial $\mathrm{nAChR}$ binding assays to demonstrate that our techniques produced results consistent with the published literature on rodents, as there were no published studies on langomorphs. These rats were 7-8 months old.
Rabbits. A total of 112 female New Zealand white specific pathogen-free rabbits were tested. Fifty-six rabbits were retired breeders of a mean age of $26.9(\mathrm{SD}=1.7)$ months and a mean weight of $4.1(\mathrm{SD}=0.4) \mathrm{kg}$ and 56 rabbits were young adults of a mean age of $4.0(\mathrm{SD}=0.0)$ months and a mean weight of $2.9(\mathrm{SD}=0.3) \mathrm{kg}$. All rabbits were purchased from Covance (Denver, PA). They were individually housed in stainless steel cages in temperature-and-humidity controlled rooms in an Association for Assessment and Accreditation of Laboratory Animal Care International (AAALAC)-approved animal facility. They had $a d$ lib access to food and water. The light/dark cycle was $12 / 12 \mathrm{~h}$. The Institutional Animal Care and Use Committee (IACUC) at Temple University approved research procedures used in this study. This research was carried out in accordance with the Guide for the Care and Use of Laboratory Animals as adopted and promulgated by the National Institutes of Health.

\section{Behavioral Testing}

Over the course of 7 days prior to training, the rabbits were gradually familiarized and adapted to Plexiglas restrainers for $30 \mathrm{~min}$ per day. Familiarization training took place in rabbits' individual cages during the first 5 days. At the end of each familiarization session, rabbits were rewarded with a treat formulated for rabbits (Kaytee Yogurt Dips). The last 2 days of familiarization took place outside the individual cages, and rabbits were fully restrained. On the seventh day, a local ophthalmic anesthetic (proparacaine hydrochloride) was applied to the left eye so that a 6-0 nylon suture loop could be placed in the temporal margin of the nictitating membrane (NM). Forty-eight rabbits (twenty-four 4-month, twenty-four 27-month) were tested in a dose-response study of MEM-3389 and were randomly assigned to groups with six 4-month-old and six 27-month-old rabbits at each dose (0 (vehicle), $0.3,1.0,3.0 \mathrm{mg} / \mathrm{kg}$ ). There were 64 rabbits in the study on the effects of galantamine, MEM-3389, and vehicle on learning and nAChRs, with ten 4-month-old and ten 27-month-old rabbits in each drug treatment group and 12 rabbits in each age category in the vehicle group.

The conditioning apparatus consisted of eight separate sound-attenuating chambers, permitting up to eight rabbits to be trained simultaneously. A speaker mounted to the wall of each chamber delivered a pure tone that was used as the conditioned stimulus (CS). The headpiece, affixed behind the rabbit's ears and under its muzzle, held a plastic tube to deliver 3 psi corneal-directed air puff unconditioned stimulus (US) and a minitorque potentiometer (San Diego Instruments, San Diego, CA) to measure the rabbit's NM/ eyeblink response. Elastic eyelid retractors kept the rabbit's eye open. The potentiometer was secured to the NM via a lever and the nylon suture loop. Analog output from the potentiometer was digitized, stored, and analyzed using a PC (Chen and Steinmetz, 1998). This system also controlled the timing and presentation of the stimuli. For all experiments, the intertrial interval was randomized and ranged between 20 and $30 \mathrm{~s}$. A single session lasted approximately $45 \mathrm{~min}$ and consisted of 90 paired CS-US trials.

The paradigm was $750 \mathrm{~ms}$ delay eyeblink classical conditioning. We use this non-optimal interstimulus interval to provide a window of opportunity to demonstrate cognition-enhancing 
drug effects in young as well as older rabbits. A $1 \mathrm{kHz}, 85 \mathrm{~dB}$ SPL tone CS sounded for $850 \mathrm{~ms}$ followed by a $100-\mathrm{ms}$ corneal air puff US that commenced $750 \mathrm{~ms}$ after CS onset. The rabbits received 10 training sessions (5 days per week for 2 weeks).

Changes in the position of the NM detected by the potentiometer were processed and stored in 3-ms bins by the computer. The program recorded a response when the $\mathrm{NM}$ moved a minimum of $0.5 \mathrm{~mm}$. A conditioned response (CR) was recorded if the response occurred between 25 and $750 \mathrm{~ms}$ after the onset of the CS. An unconditioned response alone was recorded if the response took place more than $750 \mathrm{~ms}$ after the onset of the CS. A trial was eliminated if $\mathrm{NM}$ activity crossed the response threshold within $100 \mathrm{~ms}$ prior to the onset of the CS.

\section{Drugs and Drug Administration}

The drug initially called AR-R-17779 was synthesized and supplied by Memory Pharmaceuticals as MEM-3389. Galantamine hydrobromide was supplied by Janssen Pharmaceutica, NV and Ortho-McNeil Neurologics. A previous dose-response study in our laboratory identified $3.0 \mathrm{mg} / \mathrm{kg}$ as optimal for improving eyeblink conditioning in rabbits (Woodruff-Pak and Santos, 2000). Drugs were dissolved in sterile saline and administered subcutaneously (s.c.) at $1 \mathrm{ml} / \mathrm{kg} 30 \mathrm{~min}$ before behavioral testing began. There were a total of 10 injections before the 10 training sessions, and an 11th injection was administered $30 \mathrm{~min}$ before euthanasia so that receptor binding assays would be carried out on tissue at drug levels comparable to training.

\section{nAChR Binding Assays}

Rats. Rats did not receive any behavioral training. They were euthanized by carbon dioxide overdose, and the brains were rapidly removed and dissected into temporal-parietal and frontal cortex, hippocampus, and cerebellum. Tissue was stored at $-80^{\circ} \mathrm{C}$. Membrane preparation and binding assays were identical for rats and rabbits.

Rabbits. All assays on rabbit brains were from rabbits that had received behavioral testing in $750 \mathrm{~ms}$ delay eyeblink classical conditioning for 10 daily sessions. Three days after behavioral testing, each rabbit was injected with the drug it had received for the previous 2 weeks: $3.0 \mathrm{mg} / \mathrm{kg}$ galantamine, $1.0 \mathrm{mg} / \mathrm{kg}$ MEM-3389, or $1.0 \mathrm{ml} / \mathrm{kg}$ sterile saline. Thirty minutes after injection, the rabbit was euthanized with an overdose of pentobarbital and decapitated. The brain was rapidly removed and dissected. Frontal cortex, temporal-parietal cortex, hippocampus, and cerebellum were stored at $-80^{\circ} \mathrm{C}$. For binding assays, brain tissues from each of the four sites were combined for the 10 rabbits in each drug and age group.

Membrane preparation for radioligand binding assays. Membrane preparations were performed according to Davies et al (1999). Ice cold (10\% w/v) sucrose buffer (0.32 M sucrose, $1 \mathrm{mM}$ EDTA, $0.1 \mathrm{mM}$ phenylmethyl sulfonyl fluoride (PMSF), 0.01\% (w/v) sodium azide, $\mathrm{pH} 7.4$ ) was added to weighed crude tissue. The tissue was homogenized in the sucrose buffer using a glass-Teflon homogenizer (10 strokes at 600 r.p.m.). The tissue homogenate was centrifuged at $20000 \mathrm{~g}$ for $30 \mathrm{~min}$ at $4{ }^{\circ} \mathrm{C}$. The pellet was washed twice by resuspension in $10 \%(\mathrm{w} / \mathrm{v})$ original weight phosphate buffer (50 mM phosphate, $1 \mathrm{mM}$ EDTA, $0.1 \mathrm{mM}$ PMSF, $0.01 \%(\mathrm{w} / \mathrm{v})$ sodium azide, $\mathrm{pH} 7.4)$. The tissue was homogenized with a glass-Teflon homogenizer and centrifuged again at $20000 \mathrm{~g}$ for $30 \mathrm{~min}$ at $4^{\circ} \mathrm{C}$. The final pellet was resuspended in phosphate buffer to a concentration of $\sim 6 \mathrm{ml} / \mathrm{g}$ original weight and homogenized with a glassTeflon homogenizer. Protein content was determined using Pierce BCA Protein Assay Kit (Pierce Chemical Company, Rockford, IL). The prepared membrane was stored in $1.0 \mathrm{ml}$ aliquots at $-80^{\circ} \mathrm{C}$.

Radioligand binding assay. The binding of ${ }^{3} \mathrm{H}$-labeled ligand to membranes of rat and rabbit temporal-parietal cortex, hippocampus, cerebellum, and frontal cortex was investigated using $\left[{ }^{3} \mathrm{H}\right]$ Epi and $\left[{ }^{3} \mathrm{H}\right] \mathrm{MLA}$. The assay was performed according to Davies et al (1999) and Wickramaratna et al (2004). For $\left[{ }^{3} \mathrm{H}\right] \mathrm{Epi}$, membranes were diluted in phosphate buffer to give a protein content of $0.5 \mathrm{mg}$ in a final assay volume of $0.5 \mathrm{ml}$. Total binding of $\left[{ }^{3} \mathrm{H}\right] \mathrm{Epi}$ was determined using six concentrations from 0.03 to $1.0 \mathrm{nM}$. Radioligand concentrations were prepared by serial dilution. Nonspecific binding of $\left[{ }^{3} \mathrm{H}\right]$ Epi was defined by the addition of $100 \mu \mathrm{M}$ nicotine. For $\left[{ }^{3} \mathrm{H}\right] \mathrm{MLA}$, membranes were diluted in phosphate buffer supplemented with $0.1 \%$ $(\mathrm{w} / \mathrm{v})$ BSA to a protein content of $0.5 \mathrm{mg}$ in a final assay volume of $0.5 \mathrm{ml}$. Total binding of $\left[{ }^{3} \mathrm{H}\right] \mathrm{MLA}$ was determined using six concentrations from 0.3 to $10 \mathrm{nM}$. Nonspecific binding of $\left[{ }^{3} \mathrm{H}\right] \mathrm{MLA}$ was obtained by the addition of $300 \mu \mathrm{M}$ nicotine or $100 \mu \mathrm{M}$ MLA (similar nonspecific binding).

Total binding assay volumes were $0.5 \mathrm{ml}$, consisting of $0.3 \mathrm{ml}$ of diluted membrane, $0.1 \mathrm{ml}$ phosphate buffer for total binding or $0.1 \mathrm{ml}$ of cold ligand for nonspecific binding, and $0.1 \mathrm{ml}$ of radioligand. Samples were run in duplicates for both total binding and nonspecific binding. After 90 min incubation at $0^{\circ} \mathrm{C}$, bound and free radioligands were separated by filtration with GF/B filters that had been soaked in a solution of $0.2 \%$ polyethylenimine, $0.1 \mathrm{mg}$ $\mathrm{BSA} / \mathrm{ml}$, and $50 \mathrm{mM}$ Tris for $60 \mathrm{~min}$. Filters were washed three times with ice cold $1 \times$ PBS. Radioactivity on filters was determined by liquid scintillation counting.

Specific binding was determined by the difference between nonspecific binding and total binding. Maximum binding $\left(B_{\max }\right)$ and dissociation constant $\left(K_{\mathrm{d}}\right)$, expressed in femtomole per milligram protein (fmol/mg protein) and nanomolar (nM), respectively, were determined by nonlinear regression fitting to a single-site ligand binding model found in the software Prism 3.0 (GraphPad Software Inc., San Diego, CA).

\section{Statistical Analyses}

Statistical Package for Social Sciences (SPSS) version 14 was used to carry out univariate and repeated measures analysis of variance (ANOVA) of conditioning data. There were three independent repeats for each receptor binding assay. Age and drug comparisons of $B_{\max }$ and $K_{\mathrm{d}}$ were made with one-way ANOVA for each brain site for $\left[{ }^{3} \mathrm{H}\right]$ Epi and $\left[{ }^{3} \mathrm{H}\right] \mathrm{MLA}$ using Prism 3.0 (GraphPad Software Inc., San Diego, CA). 


\section{RESULTS}

\section{Dose-Response of MEM-3389}

The number of trials to a criterion of eight CRs in nine consecutive trials was one of the dependent measures used to evaluate efficacy of the various doses of MEM-3389. A 2 (age) by 4 (drug dose) ANOVA indicated a statistically significant effect of drug dose, $\mathrm{F}(3,40)=3.32, p=0.029$ (Figure 1). The effect of age was also significant, $\mathrm{F}(1,40)=$ $7.24, p=0.010$, but the age by drug interaction effect was not significant. A 2 (age) by 4 (drug) by 10 (training sessions) repeated measures ANOVA with percentage of CRs as the dependent measure indicated a statistically significant effect of drug dose, $\mathrm{F}(3,40)=3.21, p=0.033$. The effect of age was significant, $\mathrm{F}(1,40)=14.73, p<0.001$, as was the effect of training sessions, $\mathrm{F}(9,360)=82.93$, $p<0.001$. The age by training sessions interaction effect was also significant, $\mathrm{F}(9,360)=5.04, p<0.001$, but none of the other interaction effects attained statistical significance. Post hoc analyses of the significant drug effect indicated that a dose of $1.0 \mathrm{mg} / \mathrm{kg}$ MEM-3389 was significantly better than vehicle.

\section{Galantamine, MEM-3389, and Learning}

To compare the effect of age and cognition-enhancing drugs on eyeblink conditioning, a 2 (age) by 3 (drug) by 10 (training sessions) repeated measures ANOVA was carried out using the dependent measure of percentage of CRs. The main effects of age, drug, and training sessions were all statistically significant, $\mathrm{F}(1,58)=25.53, p<0.001 ; \mathrm{F}(2,58)=$ 3.33, $p=0.043 ; \mathrm{F}(9,522)=94.13, p<0.001$, respectively (Figure $2 \mathrm{a}$ and $\mathrm{b}$ ). Four-month-old rabbits acquired

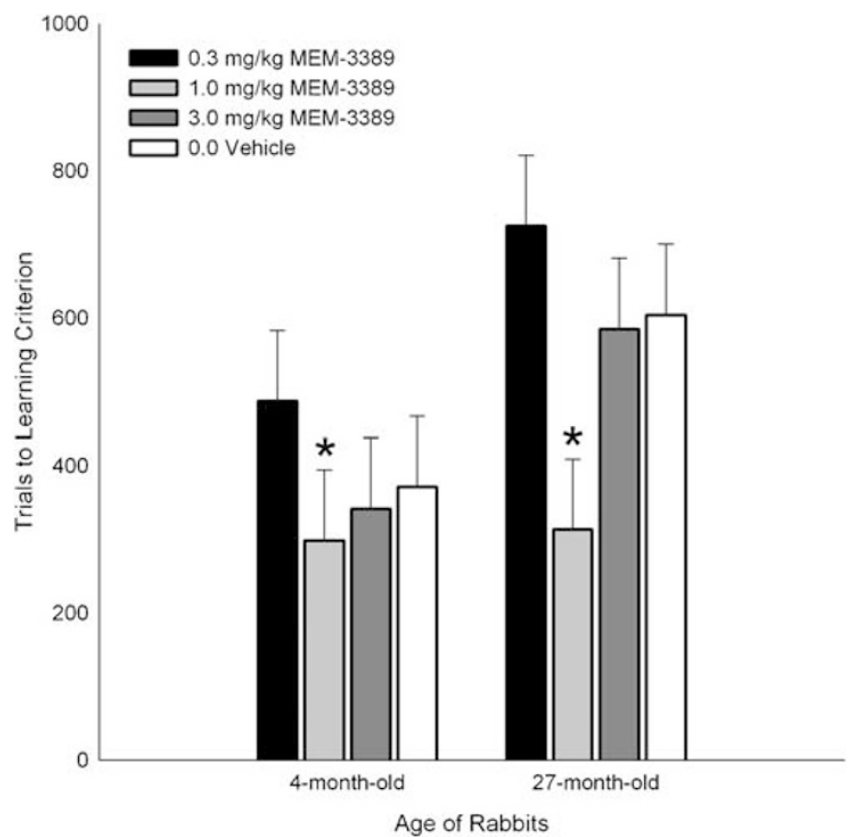

Figure I Trials to learning criterion in 4- and 27-month-old rabbits treated with four doses of MEM-3389. Number of trials to produce eight CRs in nine consecutive trials in rabbits treated with 0 (vehicle), 0.3, I.0, or $3.0 \mathrm{mg} / \mathrm{kg}$ MEM-3389. There were six rabbits in each age group at each dose. A dose of $1.0 \mathrm{mg} / \mathrm{kg}$ facilitated learning significantly. Error bars are SEM. $* p<0.05$.
CRs at a significantly higher magnitude than 27-monthold rabbits, animals treated with galantamine or MEM-3389 acquired CRs at a significantly higher magnitude than vehicle-treated animals, and over training sessions a significant increase in CRs occurred. The interaction between age and training sessions was statistically significant, $\mathrm{F}(9,522)=3.27, p<0.001$, with 4 -month-old rabbits acquiring CRs over training sessions at a faster rate than 27-month-old rabbits. The three-way interaction between age, drug, and training sessions was statistically significant, $\mathrm{F}(18,522)=2.02, p<0.008$. Post hoc analyses of the significant interaction indicated that 4- and 27-month-old rabbits treated with galantamine or MEM-3389 acquired CRs at a faster rate than vehicle-treated 4- or 27-month-old rabbits, and 4-month-old rabbits treated with galantamine and MEM-3389 performed better than 27-month-old rabbits treated with those drugs (Figure $2 \mathrm{~b}$ ). The age by drug interaction was not statistically significant.

\section{Nicotinic Receptor Binding}

$\alpha \beta$ heteromeric and $\alpha 7$ homomeric $n A C h R$ binding in four brain regions in young rats and rabbits. Since $\left[{ }^{3} \mathrm{H}\right] \mathrm{Epi}$ and $\left[{ }^{3} \mathrm{H}\right]$ MLA binding to nAChRs have not been performed in rabbit brains, we first performed binding in the rat brain to validate binding conditions. To determine the levels of nAChRs in young rat and young rabbit brains, we determined the $B_{\max }$ and $K_{\mathrm{d}}$ values of $\left[{ }^{3} \mathrm{H}\right]$ Epi (for $\alpha \beta$ heteromeric nAChRs) and $\left.{ }^{3} \mathrm{H}\right] \mathrm{MLA}$ (for $\alpha 7$ homomeric nAChRs) binding to the membrane preparations of four brain regions (frontal cortex, temporal-parietal cortex, hippocampus, and cerebellum). The young vehicle-treated rabbits had been tested in delay eyeblink conditioning, whereas the rats were not tested behaviorally.

Rats: In the rat brain regions, the $K_{\mathrm{d}}$ values of $\left[{ }^{3} \mathrm{H}\right]$ Epi binding for $\alpha \beta$ heteromeric nAChRs were $\sim 0.06 \mathrm{nM}$ and the $B_{\max }$ values were in the range of $30-70 \mathrm{fmol} / \mathrm{mg}$ protein (Table 1). In addition, the $K_{d}$ values of $\left[{ }^{3} \mathrm{H}\right]$ MLA were $1.4-1.7 \mathrm{nM}$ for the four rat brain regions and the $B_{\max }$ values ranged from 4 to $32 \mathrm{fmol} / \mathrm{mg}$ protein. These results are similar to published reports (Davies et al, 1999), and thus validated our binding conditions (Table 1).

Rabbits: In the rabbit brain regions, the $K_{\mathrm{d}}$ values of $\left[{ }^{3} \mathrm{H}\right]$ Epi binding were $0.05-0.07 \mathrm{nM}$, consistent with those in the rat. The $B_{\max }$ values $\left[{ }^{3} \mathrm{H}\right]$ Epi binding in rabbit are in the order of frontal cortex $>$ temporal-parietal cortex $>$ hippocampus $>$ cerebellum (Table 1). The rank order in the rabbit was similar to that in the rat, but the levels were lower. In addition, the affinity of $\left[{ }^{3} \mathrm{H}\right]$ MLA binding in the rabbit brain regions was similar to that in the rat brain and the $B_{\max }$ values were lower than those in the rat brain, in the order of temporal-parietal cortex $>$ frontal cortex $>$ hippocampus $>$ cerebellum (Table 1). Whereas the cerebellum was a structure of interest due to its essential involvement in eyeblink classical conditioning, the expression levels of the receptors in the cerebellum were very low (about $5 \mathrm{fmol} / \mathrm{mg}$ protein), which was barely at the detection limit of the binding assays with $\left[{ }^{3} \mathrm{H}\right]$-labeled ligands. This low expression level limited our ability to detect differences between species or effects of age or drug on cerebellar nAChRs. 


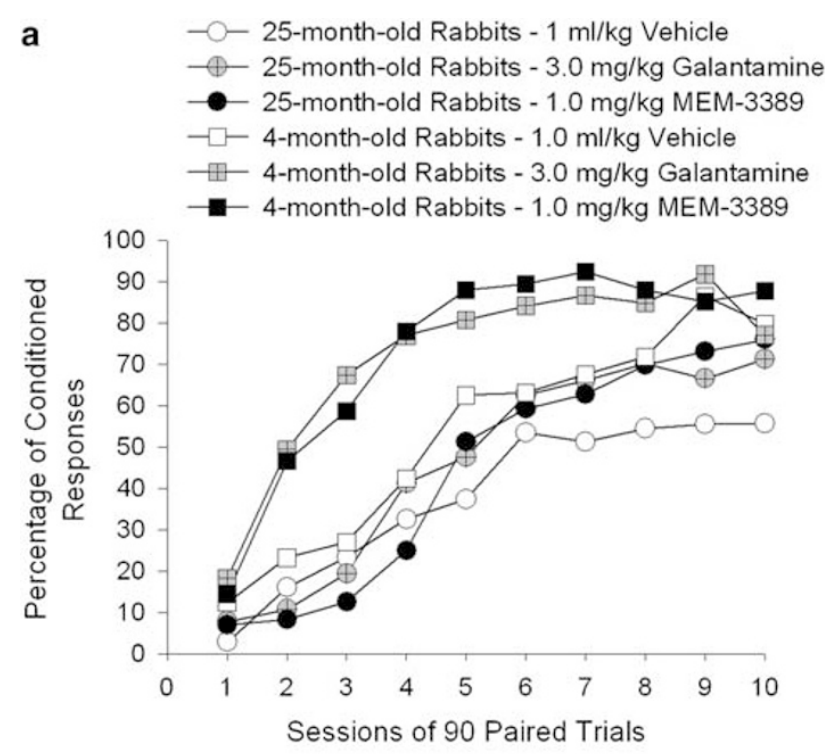

b

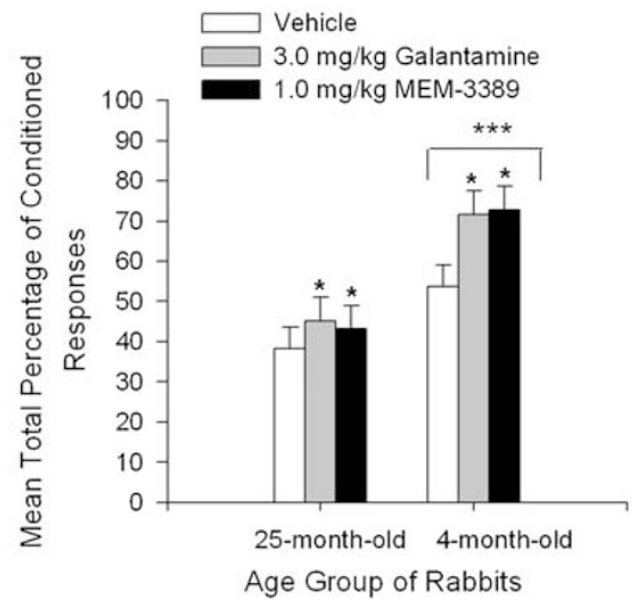

Figure 2 Eyeblink classical conditioning ( $750 \mathrm{~ms}$ delay paradigm) in 4- and 27-month-old rabbits treated with vehicle, $3.0 \mathrm{mg} / \mathrm{kg}$ galantamine, or $1.0 \mathrm{mg} / \mathrm{kg}$ MEM-3389. (a) Learning as measured with increases in CRs over 10 training sessions ( 90 trials/session). There were 10 rabbits in each age and drug-treatment group and 12 rabbits in the two vehicle groups. There were statistically significant age, drug, and training sessions effects on learning. (b) Mean total percentage of CRs for the data shown in (a) to illustrate the significant age and drug-treatment effects. Asterisks indicate that 4- and 27-month-old rabbits treated with galantamine or MEM-3389 acquired significantly more CRs than did vehicle-treated rabbits. Asterisks over the bar indicate that for all three treatment groups, 4-month-old rabbits acquired significantly more CRs than did 27-month-old rabbits. Error bars are SEM. * $p<0.05$; **** $p<0.00$ I.

Levels of $\alpha \beta$ heteromeric and $\alpha 7$ homomeric $n A C h R$ binding in four brain regions of vehicle-treated 4- and 27month-old rabbits. To examine age differences in $\alpha \beta$ heteromeric $\mathrm{nAChR}$ binding, a one-way ANOVA was carried out using three independent repeats for each age group and brain site on $B_{\max }$ values of $\left[{ }^{3} \mathrm{H}\right]$ Epi binding in four brain regions of vehicle-treated 4- and 27-month-old rabbits. There were statistically significant group differences in $B_{\max }$ values $(\mathrm{F}(7,23)=250.3 ; p<0.0001)$. Post hoc comparisons using the Tukey Multiple Comparison test indicated that the numerically lower values of 27-month-old rabbits in frontal cortex, temporal-parietal cortex, and cerebellum did not attain significance at the 0.05 level of confidence. In hippocampus, age differences in $\alpha \beta$ heteromeric nAChR binding assessed with $\left[{ }^{3} \mathrm{H}\right]$ Epi were significant $(p<0.001)$ (Figure $3 \mathrm{a}) . K_{\mathrm{d}}$ values for $\left[{ }^{3} \mathrm{H}\right]$ Epi binding in each of four brain regions of vehicle-treated 4- and 27 -month-old rabbits ranged from 0.03 to $0.10 \mathrm{nM}$. A oneway ANOVA indicated no differences in $K_{\mathrm{d}}$ values.

To examine age differences in $\alpha 7$ homomeric nAChR binding, a one-way ANOVA was carried out using three independent repeats for each age group and brain site on $B_{\max }$ values of $\left[{ }^{3} \mathrm{H}\right]$ MLA binding in each of four brain regions of vehicle-treated 4- and 27-month-old rabbits. There were statistically significant group differences in $B_{\max }$ values $(\mathrm{F}(7,23)=49.35 ; p<0.0001)$. Post hoc comparisons using the Tukey Multiple Comparison test indicated that $\alpha 7$ homomeric nAChR binding as assessed with $\left[{ }^{3} \mathrm{H}\right]$ MLA was significantly higher in 27-month-old rabbits in temporalparietal cortex $(p<0.05)$ and frontal cortex $(p<0.01$; Figure $3 \mathrm{~b}) . K_{\mathrm{d}}$ values of $\left[{ }^{3} \mathrm{H}\right] \mathrm{MLA}$ binding to $\alpha 7 \mathrm{nAChR}$ subunits in each of four brain regions of vehicle-treated 4- and 27-month-old rabbits ranged from 0.63 to $1.62 \mathrm{nM}$. A one-way ANOVA indicated no differences in $K_{\mathrm{d}}$ values.

Effects of chronic treatment of galantamine and MEM3389 on $\alpha \beta$ heteromeric $n A C h R$ binding in four brain regions of 4- and 27-month-old rabbits. Rabbits were treated with a total of 11 s.c. injections over a 2-week period with $1.0 \mathrm{ml} / \mathrm{kg}$ vehicle, $3.0 \mathrm{mg} / \mathrm{kg}$ galantamine, or $1.0 \mathrm{mg} / \mathrm{kg}$ MEM-3389. A one-way ANOVA using three independent repeats for each age group and brain site comparing drug treatment on $B_{\max }$ values of $\left[{ }^{3} \mathrm{H}\right]$ Epi binding was carried out. The effect of drug treatment was statistically significant in the frontal cortex $(\mathrm{F}(5,17)=12.15 ; p<0.0005)$, temporalparietal cortex $(\mathrm{F}(5,17)=44.76 ; p<0.0001)$, hippocampus $(\mathrm{F}(5,17)=30.29 ; \quad p<0.0001)$, and cerebellum $(\mathrm{F}(5,17)=$ $3.65 ; p=0.0386)$. Post hoc tests of the significant effects using Tukey's Multiple Comparison Test indicated that galantamine treatment significantly increased the $B_{\max }$ value of $\left[{ }^{3} \mathrm{H}\right]$ Epi binding in the frontal cortex $(p<0.01)$, temporal-parietal cortex $(p<0.001)$ and hippocampus $(p<0.001)$ of 27 -month-old rabbits (Figure $4 a)$, and the temporal-parietal cortex of 4-month-old rabbits $(p<0.05$; Figure $4 \mathrm{~b})$. Unanticipated effects of MEM-3389 on $\alpha \beta$ heteromeric nAChR binding assessed with $\left[{ }^{3} \mathrm{H}\right]$ Epi binding were also observed. MEM-3389 has been reported to be selective for $\alpha 7 \mathrm{nAChR}$ subunits in frog oocytes (Papke et al, 2004). However, in rabbits, post hoc tests indicated that MEM-3389 significantly increased $\alpha \beta$ heteromeric nAChR binding in temporal-parietal cortex $(p<0.001)$ and hippocampus ( $p<0.001)$ of 27 -month-old rabbits (Figure $4 \mathrm{a})$, and in temporal-parietal cortex of 4-month-old rabbits $(p<0.05$; Figure $4 \mathrm{~b}$ ). Although there was a statistically significant difference in $B_{\max }$ values of $\left[{ }^{3} \mathrm{H}\right]$ Epi binding in cerebellum among age and drug treatment groups, none of the post hoc comparisons between galantamine or MEM-3389 and vehicle achieved statistical significance. Again, the low expression level of receptors in the cerebellum, which was barely at the detection limit of the binding assays with $\left[{ }^{3} \mathrm{H}\right]-$ labeled ligands, limited our ability to detect drug effects on cerebellar nAChRs.

$K_{\mathrm{d}}$ values of $\left[{ }^{3} \mathrm{H}\right]$ Epi binding in each of four brain regions of 4- and 27-month-old rabbits treated with galantamine or 
Table I Mean $\pm S E$ of the Mean of $B_{\max }$ for Three Independent Experiments Using $\left[{ }^{3} \mathrm{H}\right]$ Epibatidine and $\left[{ }^{3} \mathrm{H}\right]$ Methyllycaconitine Binding in Four Brain Regions in Young Naïve Rats and Young Rabbits Trained in Eyeblink Classical Conditioning

\begin{tabular}{|c|c|c|c|c|c|}
\hline \multirow[b]{2}{*}[{}^{3}\mathrm{H}]{ ligands } & \multirow[b]{2}{*}{ Brain regions } & \multicolumn{2}{|l|}{ Rats } & \multicolumn{2}{|c|}{ 4-month-old rabbits } \\
\hline & & $B_{\max }(\mathrm{fmol} / \mathrm{mg}$ protein) & $K_{\mathrm{d}}(\mathrm{nM})$ & $B_{\max }{ }^{a}(f m o l / m g$ protein) & $K_{\mathrm{d}}(\mathrm{nM})$ \\
\hline & Temporal-parietal cortex & $62.4 \pm 1.8$ & $0.06 \pm 0.0$ & $51.9 \pm 0.9$ & $0.06 \pm 0.0$ \\
\hline & Hippocampus & $49.7 \pm 2.9$ & $0.05 \pm 0.0$ & $31.5 \pm 0.9$ & $0.06 \pm 0.0$ \\
\hline \multirow{4}{*}[{}^{3}\mathrm{H}]{$\mathrm{MLA}$} & Frontal cortex & $31.83 \pm 9.0$ & $1.69 \pm 1.0$ & $16.37 \pm 1.2$ & $0.87 \pm 0.2$ \\
\hline & Temporal-parietal cortex & $23.83 \pm 1.9$ & $1.38 \pm 0.6$ & $21.83 \pm 0.8$ & $0.63 \pm 0.1$ \\
\hline & Hippocampus & $26.2 \pm 2.8$ & $1.48 \pm 0.4$ & $11.46 \pm 1.0$ & $1.05 \pm 0.4$ \\
\hline & Cerebellum & $4.9^{\mathrm{b}}$ & $1.5^{\mathrm{b}}$ & $5.47 \pm 2.0$ & $1.62 \pm 1.0$ \\
\hline
\end{tabular}

aData also shown as young controls in Figures 3-5.

${ }^{b}$ One experiment.

MEM-3389 ranged from 0.03 to $0.12 \mathrm{nM}$. A one-way ANOVA indicated that $K_{\mathrm{d}}$ values of $\left[{ }^{3} \mathrm{H}\right]$ Epi binding to $\alpha \beta$ heteromeric nAChR were not changed by drug treatment (data not shown). These results indicate that galantamine and MEM-3389 increase receptor number of $\alpha \beta$ heteromeric nAChRs in some rabbit brain regions without changing binding affinity of the receptors.

Effects of chronic treatment with galantamine and MEM3389 on $\alpha 7$ homomeric $n A C h R$ binding in four brain regions in 4- and 27-month-old rabbits. A one-way ANOVA using three independent repeats for each age group and brain site comparing drug treatment on the $B_{\max }$ values of $\left[{ }^{3} \mathrm{H}\right] \mathrm{MLA}$ binding was carried out. The effect of drug treatment was statistically significant in the frontal cortex $(\mathrm{F}(5,17)=27.69 ; p<0.0001)$, temporal-parietal cortex $(\mathrm{F}(5,17)=9.87 ; p=0.0013)$, and hippocampus $(\mathrm{F}(5,17)=$ $10.10 ; p=0.0012)$, but not in cerebellum, possibly due to insensitivity of the assays. Post hoc tests of the significant effects using Tukey's Multiple Comparison Test indicated that $B_{\max }$ values of $\left[{ }^{3} \mathrm{H}\right] \mathrm{MLA}$ binding for 27 -month-old rabbits with galantamine treatment increased only in hippocampus $(p<0.05$; Figure $5 \mathrm{a})$. Similarly, post hoc tests of the significant effects of $\left[{ }^{3} \mathrm{H}\right]$ MLA binding in $27-$ monthold rabbits indicated that MEM-3389 treatment increased $B_{\max }$ values only in hippocampus $(p<0.05$; Figure $5 \mathrm{a})$. In 4-month-old rabbits, galantamine treatment was associated with increased $B_{\max }$ values of $\left[{ }^{3} \mathrm{H}\right]$ MLA binding in frontal cortex $(p<0.05)$, temporal-parietal cortex $(p<0.05)$, and hippocampus $(p<0.05$; Figure 5b). MEM-3389 treatment also increased $B_{\max }$ values of $\left[{ }^{3} \mathrm{H}\right]$ MLA binding in young rabbits in frontal cortex $(p<0.001)$, temporal-parietal cortex $(p<0.01)$, and hippocampus $(p<0.05$; Figure $5 b)$.

$K_{\mathrm{d}}$ values of $\left[{ }^{3} \mathrm{H}\right]$ MLA binding in each of four brain regions of 4- and 27-month-old rabbits treated with galantamine or MEM-3389 ranged from 0.67 to $1.45 \mathrm{nM}$. A one-way ANOVA indicated that $K_{d}$ values of $\left[{ }^{3} \mathrm{H}\right] \mathrm{MLA}$ binding were not changed by these two drugs.

These results demonstrate that galantamine and MEM3389 increase receptor level of $\alpha 7$ homomeric nAChRs, but not receptor binding affinity.

\section{Learning and Nicotinic Receptor Binding Relationships}

To reduce variability due to individual rabbit differences in nAChR levels, we pooled tissues from frontal cortex, temporal-parietal cortex, hippocampus, and cerebellum for each age and drug treatment. Pooling of tissue at various brain sites precluded our ability to relate individual learning performance with individual binding data. To relate learning to binding data, performance as assessed by mean total percentage of CRs for each age and drug treatment group (Figure 2b) was compared to nAChR binding in the four brain regions. Statistically significant improvement in learning in 4-month-old rabbits occurred along with significantly increased $\alpha \beta$ heteromeric nAChR binding in temporal-parietal cortex and increased $\alpha 7$ homomeric $\mathrm{nAChR}$ binding in frontal and temporal-parietal cortex and hippocampus. Statistically significant improvement in learning in 27-month-old-rabbits occurred along with significantly increased $\alpha \beta$ heteromeric nAChR binding in frontal and temporal-parietal cortex and hippocampus, and in $\alpha 7$ homomeric nAChR binding in hippocampus.

\section{DISCUSSION}

Chronic treatment of 4- and 27-month-old rabbits with galantamine or MEM-3389 improved learning in $750 \mathrm{~ms}$ delay eyeblink classical conditioning and increased levels of $\alpha \beta$ heteromeric and $\alpha 7$ homomeric nAChRs as assessed with $\left[{ }^{3} \mathrm{H}\right]$ Epi and $\left[{ }^{3} \mathrm{H}\right] \mathrm{MLA}$, respectively. Although epibatidine is a non-selective agonist at most neuronal $\alpha \beta$ heteromeric $\mathrm{nAChR}$ receptors, $\alpha 4 \beta 2 \mathrm{nAChRs}$ are the predominant type of the high-affinity nAChRs in the brain (Whiting and Lindstrom, 1986), and biological effects of epibatidine appear to be mediated largely by $\alpha 4 \beta 2 \mathrm{nAChRs}$.

In vehicle-treated 27-month-old rabbits, there were significantly lower levels of $\alpha \beta$ heteromeric nAChRs in hippocampus, in comparison to 4-month-old rabbits, which is consistent with research in several species. Compared to 27-month-old rabbits, 4-month-old rabbits had significantly lower levels of $\alpha 7$ homomeric nAChRs in both frontal and temporal-parietal cortex. To the best of our knowledge, 

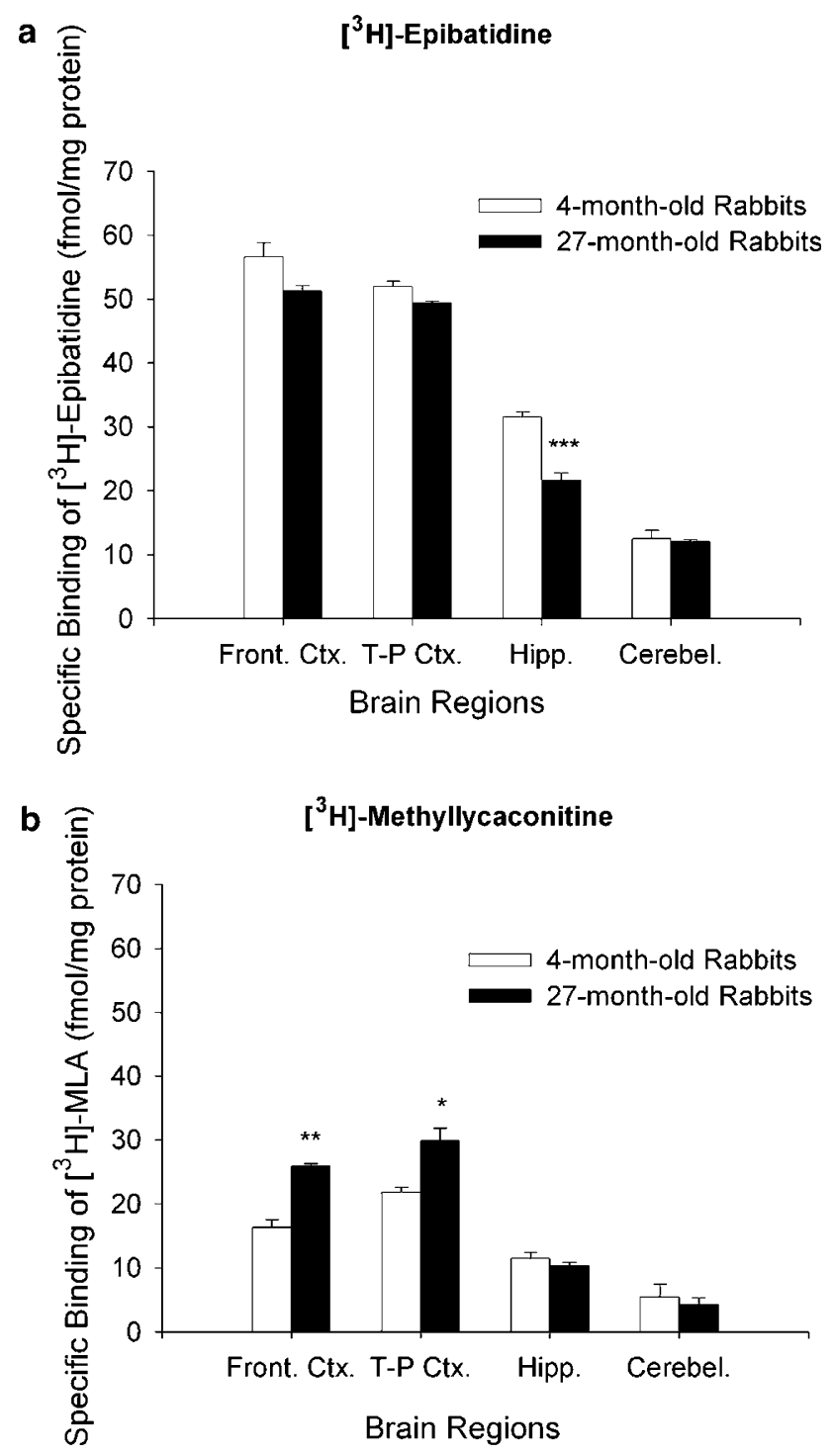

Figure 3 Comparison of $\left[{ }^{3} \mathrm{H}\right]$ Epi and $\left[{ }^{3} \mathrm{H}\right] \mathrm{MLA}$ binding in four brain regions of 4- and 27-month-old rabbits. $B_{\max }$ values for (a) $\left.{ }^{3} \mathrm{H}\right]$ Epi binding for $\alpha 4 \beta 2 n A C h R s$ and (b) $\left.{ }^{3} \mathrm{H}\right] \mathrm{MLA}$ binding for $\alpha 7 \mathrm{nAChRs}$ in four brain regions (frontal cortex, temporal-parietal cortex (T-P cortex), hippocampus, and cerebellum) in 4- and 27-month-old rabbits. Each bar represents the mean $B_{\max }$ value for three independent experiments. Error bars are SEM. ${ }^{*} p<0.05 ; * * * 0.01$; ***** $p<0.001$.

this is the first report on age differences in levels of $\alpha \beta$ heteromeric and $\alpha 7$ homomeric nAChRs in rabbit brains.

Treatment with galantamine and MEM-3389 ameliorated learning impairment in 27-month-old rabbits. Significantly increased levels of $\alpha \beta$ heteromeric nAChRs and $\alpha 7$ homomeric nAChRs were consistently found in the hippocampus in 27-month-old rabbits treated with galantamine and MEM-3389. In addition, galantamine treatment was associated with upregulation of $\alpha \beta$ heteromeric $\mathrm{nAChRs}$ in frontal and temporal-parietal cortex. MEM-3389 treatment was also associated with upregulation of $\alpha \beta$ heteromeric nAChRs in temporal-parietal cortex. Amelioration of learning impairment in older rabbits was associated with upregulation of $\alpha \beta$ heteromeric nAChRs in three brain sites along with upregulation of $\alpha 7$ homomeric nAChRs in the hippocampus. In 4-month-old rabbits that are already

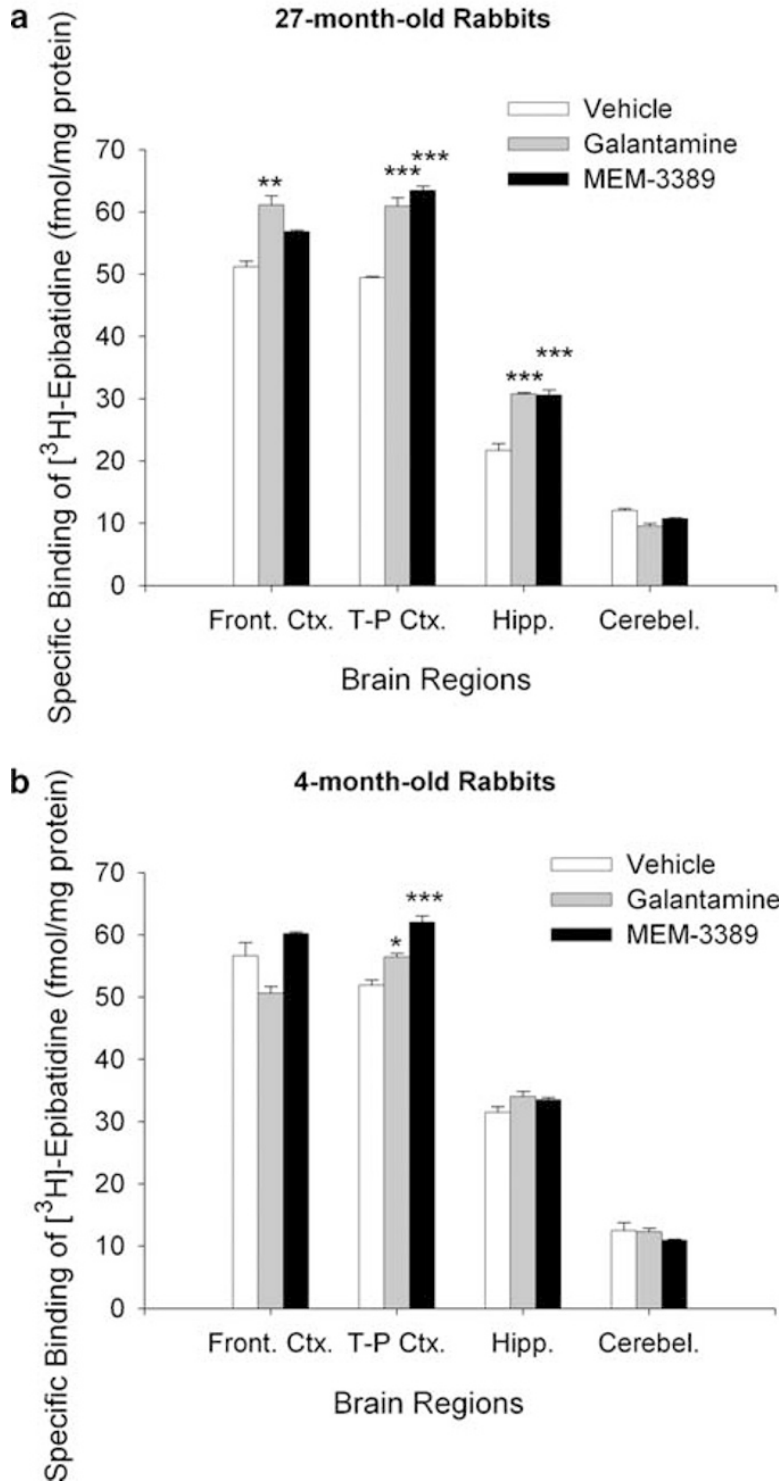

Figure 4 Effect of galantamine and MEM-3389 on expression of $\alpha 4 \beta 2 n A C h R s$ in four brain regions of (a) 27- and (b) 4-month-old rabbits. $B_{\max }$ values for $\left[{ }^{3} \mathrm{H}\right]$ Epi binding for $\alpha 4 \beta 2 \mathrm{n} A \mathrm{ChRs}$ were determined for frontal cortex, temporal-parietal cortex (T-P cortex), hippocampus, and cerebellum. Each bar represents the mean $B_{\max }$ value from three independent experiments for galantamine, MEM-3389, and vehicle. Vehicle data are also shown in Figure 2. Error bars are SEM. $* p<0.05$; $* * p<0.0$ I; **** $p<0.00$ I.

performing at high levels, it was primarily upregulation of $\alpha 7$ homomeric nAChRs that was associated with significant facilitation of learning by galantamine or MEM-3389.

\section{Comparability of nAChR Levels in Young Rats and Rabbits}

In a review of brain nAChRs, Gotti et al (2006) summarized the composition, localization, and number of native $\mathrm{nAChR}$ subunits in different brain regions of five species: humans, monkeys, rats, mice, and chickens. Species differences in cortical levels of $\alpha \beta$ heteromeric and $\alpha 7$ homomeric nAChRs were substantial (approximately 10-fold). Humans and 
$\alpha 7$ Homomeric nAChRs

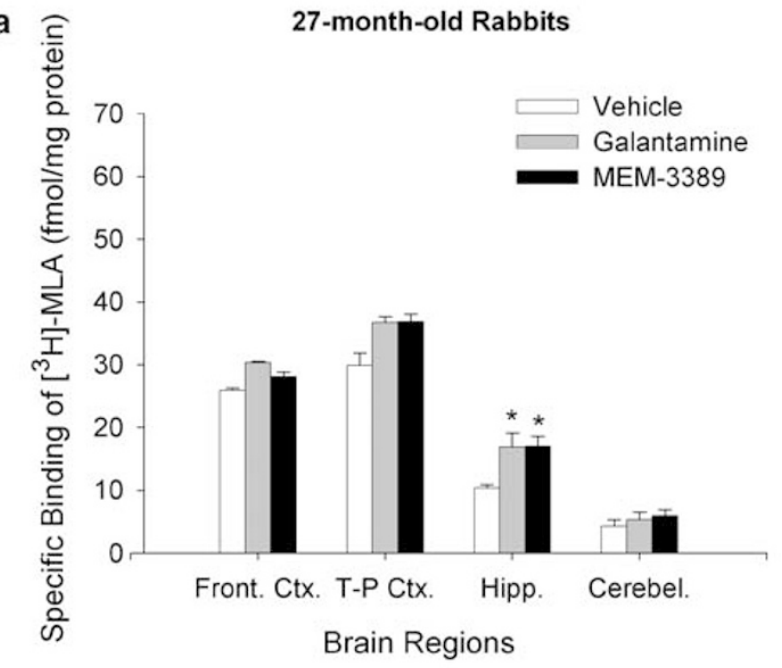

b

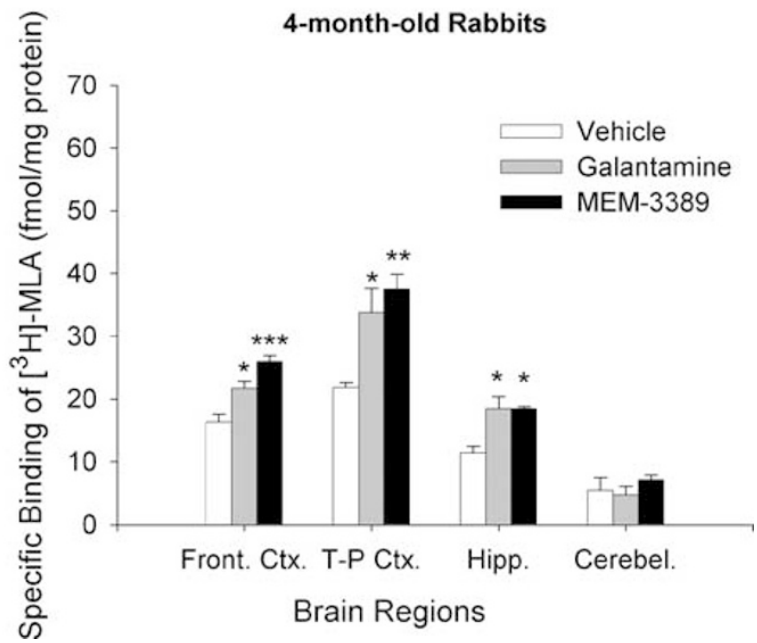

Figure 5 Effect of galantamine and MEM-3389 on levels of $\alpha 7 \mathrm{nAChRs}$ in four brain regions of (a) 27- and (b) 4-month-old rabbits. $B_{\max }$ values of $\left.{ }^{3} \mathrm{H}\right] \mathrm{MLA}$ binding for $\alpha 7 n A C h R s$ were determined for frontal cortex, temporal-parietal cortex (T-P cortex), hippocampus, and cerebellum. Each bar represents the mean $B_{\max }$ value from three independent experiments galantamine, MEM-3389, and vehicle. Vehicle data are also shown in Figures 2 and 3. Error bars are SEM. $* p<0.05$; $* * p<0.01$; **** $p<0.00$ I.

monkeys had the lowest $B_{\max }$ values for $\alpha \beta$ heteromeric and $\alpha 7$ homomeric nAChRs, rodents had intermediate values, and chicks had the highest values. On this continuum, rabbits fall between monkeys and rats, but the values for rabbits are closer to those of rats. The levels of $\alpha \beta$ heteromeric nAChRs labeled with $\left[{ }^{3} \mathrm{H}\right] \mathrm{Epi}$ and $\alpha 7$ homomeric nAChRs labeled with $\left[{ }^{125} \mathrm{I}\right] \alpha$-bungarotoxin or $\left[{ }^{3} \mathrm{H}\right] M L A$ in rat brain regions have slight variations in different reports (Davies et al, 1999; Gotti et al, 2006). Our data show that the levels of $\left[{ }^{3} \mathrm{H}\right]$ Epi and $\left[{ }^{3} \mathrm{H}\right]$ MLA binding sites did not differ much between rats (rodent species) and rabbits (langomorph species; Table 1). Thus, although we compared levels of $\alpha \beta$ heteromeric and $\alpha 7$ homomeric nAChRs in rabbits that had been tested behaviorally to rats that were not behaviorally tested, the values were similar. It seems unlikely that eyeblink classical conditioning affected levels of $\alpha \beta$ heteromeric and $\alpha 7$ homomeric nAChRs in rabbits, but we did not assay the brains of untrained rabbits to determine the effect of training.

\section{Age Differences in $\alpha \beta$ Heteromeric and $\alpha 7$ Homomeric nAChRs}

Compared with 4-month-old rabbits, 27-month-old rabbits have significantly lower $\alpha \beta$ heteromeric nAChR binding in the hippocampus, and they have numerically lower $\alpha \beta$ heteromeric $\mathrm{nAChR}$ binding in frontal and temporal-parietal cortex. Our observations for $\alpha \beta$ heteromeric nAChRs are consistent with studies in a number of species. During normal aging, there is a diminution in the expression of highaffinity binding sites in the brain that has been reported in humans (eg, Giacobini, 1992), monkeys (Wagster et al, 1990), and rodents (Araujo et al, 1990; Birtsch et al, 1997; Zhang et al, 1990). In mice, in the CBA strain, there was a dramatic loss of $\alpha \beta$ heteromeric nAChRs in the 28-month-old hippocampus (Gahring et al, 2005; Rogers et al, 1998).

The 27-month-old rabbits in this study had significantly higher $\alpha 7$ homomeric $\mathrm{nAChR}$ binding in frontal and temporal-parietal cortex in contrast to numerically lower $\alpha 7 n A C h R$ binding in hippocampus and cerebellum. Most studies of $\alpha 7 n A C h R s$ report age-related stability in these receptors in the four brain regions examined in our research. Human $\alpha 7 n A C h R s$ showed stability from the fetal period to late old age in frontal cortex and cerebellum (Falk et al, 2003), and in hippocampus (Court et al, 1997; Nordberg and Winblad, 1986). Comparisons of CBA and C57BL/6 mice revealed that loss of hippocampal $\alpha 7$ homomeric nAChRs is strain dependent, with C57BL/6 mice showing stability at 28 months and with CBA mice showing dramatic loss (Gahring et al, 2005). We found no reports of age-related increases in $\alpha 7 n A C h R s$ in any species. Our observation of statistically significant higher $B_{\max }$ values of $\left[{ }^{3} \mathrm{H}\right]$ MLA binding in frontal and temporal-parietal cortex in 27 -month-old rabbits was reliable over three independent repeated experiments (Figure 3). However, the results are based on 10 female 27 -month-old rabbits. Data on male and female rabbits, younger and older than 27 months, are required to determine whether there is stability in $\alpha 7$ homomeric nAChRs in New Zealand white rabbits or age-related increment and later-life decline in relation to 27 -month-old values.

\section{Galantamine and nAChRs}

Galantamine increased receptor levels of both $\alpha \beta$ heteromeric and $\alpha 7$ homomeric nAChRs in at least one age group of rabbits in frontal and temporal-parietal cortex and hippocampus (Figures 4 and 5). These results are consistent with previous results in 29-month-old rabbits treated with 16 s.c. injections of $3.0 \mathrm{mg} / \mathrm{kg}$ galantamine that showed increased expression of cortical $\alpha \beta$ heteromeric nAChRs labeled by $\left[{ }^{3} \mathrm{H}\right]$ Epi (Woodruff-Pak et al, 2001). Other investigators have reported associations between galantamine administration and nAChR upregulation. Chronic treatment of old rats with galantamine increased $B_{\max }$ for $\left[{ }^{3} \mathrm{H}\right]$ nicotine binding in frontal cortex and hippocampus (Barnes et al, 2000). In rat cortical culture, galantamine increased the number of cells expressing $\alpha \beta$ heteromeric and $\alpha 7$ homomeric nAChR subunits (Kume et al, 2005). Using the Morris water maze and receptor autoradiography, 
Hernandez et al (2006) demonstrated that galantamine enhanced spatial learning in rats and increased $\alpha \beta$ heteromeric nAChR binding.

\section{MEM-3389 also Affected $\alpha \beta$ Heteromeric nAChRs}

MEM-3389 significantly upregulated $\left[{ }^{3} \mathrm{H}\right]$ Epi binding sites in cortex and hippocampus in 27-month-old rabbits and in temporal-parietal cortex in 4-month-old rabbits (Figure 4), in addition to upregulating $\left[{ }^{3} \mathrm{H}\right]$ MLA binding sites in hippocampus and cortex (Figure 5). These results indicate that MEM-3389 may affect not only $\alpha 7 n$ AChRs directly but also $\alpha \beta$ heteromeric $\mathrm{nAChRs}$ in either a direct or indirect manner. Curiously, the $\alpha 7 \mathrm{nAChR}$ agonist DMAC also increased $\left[{ }^{3} \mathrm{H}\right]$ Epi binding sites in SH-SY5Y cells following 4 days of treatment (Ridley et al, 2001).

\section{Aging, Eyeblink Conditioning, and the Cerebellum}

Normal aging affects mammalian eyeblink conditioning through age-related deficits in the cerebellum (eg, WoodruffPak, 2006). It has been assumed that drugs that ameliorate impaired acquisition of CRs do so through basal forebrain cholinergic mechanisms via the hippocampus to the cerebellum. Additional evidence for the role of cortical structures in ameliorating impaired conditioning is provided with data from the present study. Older rabbits had poorer learning and lower $\alpha \beta$ heteromeric nAChR binding in hippocampus than 4-month rabbits. Both galantamine and MEM-3389 ameliorated impaired learning in 27-month rabbits and increased expression of temporal-parietal and hippocampal $\alpha \beta$ heteromeric nAChRs and hippocampal homomeric $\alpha 7 n A C h R s$. The major basal forebrain acetylcholine projections are to cortex, including medial temporal lobes and hippocampus (via the medial septum). However, there is also a second source of acetylcholine to the brain, the pedunculopontine, and laterodorsal tegmental nuclei that have projections to the cerebellum.

Anterograde and retrograde labeling of choline acetyltransferase-positive cerebellar mossy fiber rosettes in several species including the rabbit indicate that these cells originate from the pedunculopontine nucleus (Barmack et al, 1992; Jaarsma et al, 1997). $\left[{ }^{3} \mathrm{H}\right]$ nicotine and $\left[{ }^{3} \mathrm{H}\right]$ cytisine autoradiography was used to analyze the distribution of rabbit cerebellar nAChRs. As reported in the present study, the relative density of labeling in the cerebellum was low compared to cerebral cortex. Jaarsma et al (1997) found that nAChR labeling was concentrated in the cerebellar cortical granular layer and in the deep cerebellar nuclei.

The essential site for eyeblink conditioning is in the deep cerebellar nuclei. The techniques we used in the present study, radioligand receptor binding for neuronal $\alpha \beta$ heteromeric nAChRs ([ $\left.\left.{ }^{3} \mathrm{H}\right] \mathrm{Epi}\right)$ and $\alpha 7$ homomeric nAChRs $\left(\left[{ }^{3} \mathrm{H}\right] \mathrm{MLA}\right)$, did not detect differences in cerebellum because expression level in the cerebellum is low and is barely at the detection limit of these binding assays. We cannot rule out the possibility that drugs affecting $\mathrm{nAChRs}$ and acquisition of conditioned eyeblink responses are acting in the cerebellum as well as in cortical brain sites and will aim to evaluate this possibility with more sensitive assays in future research.

\section{Relationships Between Age, Learning, and nAChRs}

Nicotinic acetylcholine systems have been found to be important for learning and memory functions. An agerelated decrease in the number of $\alpha \beta$ heteromeric nAChRs in brain regions such as cortex and hippocampus is thought to contribute to cognitive impairment. We found an association between age differences in binding of $\alpha \beta$ heteromeric nAChRs, drug treatment-related increases in nAChR binding, and learning. At 27 months of age, vehicle-treated rabbits had significantly lower receptor levels of $\alpha \beta$ heteromeric nAChRs in the hippocampus and significantly poorer learning than young vehicle-treated rabbits. Chronic treatment with galantamine or MEM-3389 ameliorated learning impairment in these older rabbits as well as increased receptor levels of $\alpha \beta$ heteromeric nAChRs in cortex and hippocampus. Treatment with these two drugs elevated the performance of 27-month-old rabbits to the level of vehicle-treated 4-month-old rabbits (Figure 2). Both drugs significantly increased binding of $\alpha \beta$ heteromeric nAChRs to the levels comparable to those of young vehicle-treated rabbits (Figure 4).

Cognition-enhancing drugs also affected homomeric $\alpha 7 n A C h R s$, and significant increases in receptor binding were especially evident in young rabbits (Figure 5). These results are consistent with studies in rats. Hernandez et al (2006) demonstrated that chronic treatment with nicotine improved memory performance in the Morris water maze and increased $\left[{ }^{3} \mathrm{H}\right]$ Epi and $\left[{ }^{125} \mathrm{I}\right] \alpha$-bungarotoxin autoradiographic densities in several brain regions. The knockdown of rat $\alpha 7 \mathrm{nAChR}$ subunits with antisense resulted in a decrease in $\left[{ }^{3} \mathrm{H}\right] \mathrm{MLA}$ binding sites by $42 \%$ in hippocampus and $25 \%$ in cortex and impaired acquisition on the Morris water maze (Curzon et al, 2006).

Drug-treated younger rabbits showed significantly improved learning over vehicle-treated young rabbits. In the $750 \mathrm{~ms}$ delay classical conditioning paradigm, young vehicle-treated rabbits are close to ceiling levels of performance. In our experience with a number of cognition-enhancing drugs, very few (galantamine (Woodruff-Pak et al, 2001) and now MEM3389) facilitate learning in this paradigm in young rabbits. Drug treatment in young rabbits also improved learning to levels that were significantly better than learning in drugtreated 27-month-old rabbits. Receptor binding of $\alpha \beta$ heteromeric nAChRs in the hippocampus of young rabbits did not increase with drug treatment. The only significant increase in receptor levels of $\alpha \beta$ heteromeric nAChRs in young rabbits was in temporal-parietal cortex. The receptors in young rabbit brains showing the greatest plasticity in response to galantamine and MEM-3389 were homomeric $\alpha 7 n$ AChRs. Associated with the superior learning of drug-treated young rabbits were significant increases in receptor binding of homomeric $\alpha 7 \mathrm{nAChRs}$ in frontal cortex, temporal-parietal cortex, and hippocampus. Only hippocampal homomeric $\alpha 7 \mathrm{nAChRs}$ had significant increases in receptor binding in 27-month-old rabbits.

The role of the hippocampus in eyeblink classical conditioning is called 'modulatory', because manipulations of the hippocampus can impair or enhance the rate of acquisition (Berger et al, 1986). The memory trace itself is not in the hippocampus, but the hippocampus can markedly influence the storage process (reviewed in Thompson, 
2005). In rabbits, age-related deficits in hippocampal electrophysiology have been associated with impairments in eyeblink conditioning (Power et al, 2002). Our data, showing increased binding of $\alpha \beta$ heteromeric and $\alpha 7$ homomeric nAChRs in the hippocampus of 27-month-old rabbits treated with galantamine or MEM-3389, indicate that these drugs ameliorate learning impairment at least in part by potentiating hippocampal $\alpha \beta$ and $\alpha 7 \mathrm{nAChRs}$.

What is new in these results is the association of highly optimized performance of young rabbits with significant increases in receptor binding of $\alpha 7$ homomeric nAChRs in cortical brain sites as well as in the hippocampus. Both galantamine (Popa et al, 2006) and MEM-3389 (Papke et al, 2004) increase binding of $\alpha 7$ homomeric nAChRs. Frontal and temporal-parietal cortex of drug-treated young rabbits as well as hippocampus showed significant increases in receptor binding of $\alpha 7$ homomeric nAChRs, whereas $\alpha 7$ binding in cortical sites in drug-treated older rabbits was not different from vehicle-treated older rabbits. Electrophysiological (Powell et al, 1996), pharmacological (Takehara-Nishiuchi et al, 2006), and lesion (Simon et al, 2005; Weible et al, 2000) studies of the role of frontal cortex in eyeblink conditioning have demonstrated involvement of prefrontal cortex. Our data indicate that the frontal cortex in addition to the hippocampus may be a site of modulation of CRs. Treatments that optimize functioning in prefrontal cortex, such as drugs that increase receptor binding of nAChRs, may improve learning.

To date, our results indicate that 27-month-old rabbits retain plasticity to increase receptor binding of $\alpha \beta$ heteromeric nAChRs in the hippocampus where they had significant loss of $\alpha \beta$ nAChRs, compared with 4-month-old rabbits. In particular, $3.0 \mathrm{mg} / \mathrm{kg}$ of galantamine or $1.0 \mathrm{mg} / \mathrm{kg}$ MEM-3389 administered chronically to older rabbits returned binding of $\alpha \beta$ heteromeric nAChRs in the hippocampus to levels observed in young vehicle-treated rabbits. In older rabbit brains, there was also increased receptor binding of $\alpha \beta$ heteromeric nAChRs in frontal and temporalparietal cortex - sites that showed no age-related deficits in $\alpha \beta$ heteromeric nAChRs. Whereas increased receptor binding of $\alpha \beta$ heteromeric nAChRs was associated with significant amelioration of learning impairment in drugtreated older rabbits, their learning proficiency was still below that of drug-treated young rabbits who showed increased receptor binding of $\alpha 7$ homomeric nAChRs. Plasticity in $\alpha 7$ homomeric nAChRs caused by chronic administration of galantamine or MEM-3389 was associated with highly optimized learning in young rabbits. Cortical as well as hippocampal upregulation of nAChRs in drugtreated rabbits was associated with improvement in learning over vehicle-treated rabbits. Increases in expression of $\alpha \beta$ heteromeric nAChRs occurred at the most brain sites in the case of amelioration of learning impairment in 27-monthold rabbits. Increases in expression of $\alpha 7$ homomeric nAChRs occurred at the most brain sites in the case of facilitation or optimization of learning in 4-month-old rabbits. These results indicate that substrates underlying plasticity at different ages may vary. In the present study, $\alpha \beta$ heteromeric nAChRs were most consistently associated with amelioration of learning impairment in older rabbits, whereas $\alpha 7$ homomeric nAChRs were most associated with optimization of learning in young rabbits.

\section{ACKNOWLEDGEMENTS}

We thank Susan Seta, LaToya Roker, Renee Procopio, and Steve Purcell for their assistance with rabbit familiarization training and behavioral testing. We gratefully acknowledge Janssen Pharmaceutica, NV, and Ortho-McNeil Neurologics for supplying galantamine and Memory Pharmaceuticals for supplying MEM-3389, formerly identified as AR-R-17779. This research was supported by grants from the National Institute on Aging, 1 R01 AG021925 and 1 R01 AG023742 to DSW-P and from the National Institute on Drug Abuse, R01 DA17302 and P30 DA 13429 to L-YL-C.

\section{DISCLOSURE/CONFLICT OF INTEREST}

None of the authors of this paper have any potential conflicts of interest that would influence the objectivity of this report.

\section{REFERENCES}

Araujo DM, Lapchak PA, Meaney MJ, Collier B, Quirion R (1990). Effects of aging on nicotinic and muscarinic autoreceptors function in the rat brain: relationship to presynaptic cholinergic markers and binding sites. J Neurosci 10: 3069-3078.

Barmack NH, Baughman RW, Eckenstein FP (1992). Cholinergic innervation of the cerebellum of rat, rabbit, cat, and monkey as revealed by choline acetyltransferase activity and immunohistochemistry. J Comp Neurol 317: 233-249.

Barnes CA, Meltzer J, Houston F, Orr G, McGann K, Wenk GL (2000). Chronic treatment of old rats with donepezil or galantamine: effects on memory, hippocampal plasticity and nicotinic receptors. Neuroscience 99: 17-23.

Berger TW, Berry SD, Thompson FF (1986). Role of the hippocampus in classical conditioning of aversive and appetitive behaviors. In: Isaacson RL, Pribram KH (eds). The Hippocampus. Plenum: New York. pp 203-239.

Birtsch C, Wevers A, Traber J, Maelicke A, Bloch W, Schröder H (1997). Expression of $\alpha 4-1$ and $\alpha 5$ nicotinic cholinoceptor mRNA in the aging rat cerebral cortex. Neurobiol Aging 18: 335-342.

Changeux JP, Bertrand D, Corringer PJ, Dehaene S, Edelstein S, Lena C et al (1998). Brain nicotinic receptors: structure and regulation, role in learning and reinforcement. Brain Res Rev 26: 198-216.

Chen G, Steinmetz JE (1998). A general-purpose computer system for behavioral conditioning and neural recording experiments. Behav Res Methods Instrum Comput 30: 384-391.

Christian KM, Thompson RF (2003). Neural substrates of eyeblink conditioning: acquisition and retention. Learn Mem 11: 427-455.

Conroy WG, Vernallis AB, Berg DK (1992). The $\alpha 5$ gene product assembles with multiple acetylcholine receptor subunits to form distinctive receptor subtypes in brain. Neuron 9: 679-691.

Court J, Lloyd S, Johnson M, Griffiths M, Birdsall NJ, Piggott MA et al (1997). Nicotinic and muscarinic cholinergic receptor binding in the human hippocampal formation during development and aging. Dev Brain Res 90: 159-167.

Couturier S, Bertrand D, Matter JM, Hernandez MC, Bertrand S, Millar N et al (1990). A neuronal nicotinic acetylcholine receptor subunit $(\alpha 7)$ is developmentally regulated and forms a homooligomeric channel blocked by $\alpha$-BTX. Neuron 5: 847-856.

Curzon P, Anderson DJ, Nikkel AL, Fox GB, Gopalakrishnan M, Decker MW et al (2006). Antisense knockdown of the rat alpha7 nicotinic acetylcholine receptor produces spatial memory impairment. Neurosci Lett 410: 15-19.

Davies RL, Hardick DJ, Blagbrough IS, Potter B, Wolstenholme AJ, Wonnacott S (1999). Characterisation of the binding of 
$\left[{ }^{3} \mathrm{H}\right]$-methyllycaconitine: a new radiolgiand for labeling $\alpha 7$-type neuronal nicotinic acetylcholine receptors. Neuropharmacology 38: 679-690.

Falk L, Nordberg A, Seiger A, Kjaeldgaard A, Hellström-Lindahl E (2003). Higher expression of $\alpha 7$ nicotinic acetylcholine receptors in human fetal compared to adult brain. Dev Brain Res 142: 151-160.

Gahring LC, Persiyanov K, Rogers SW (2005). Mouse strain-specific changes in nicotinic receptor expression with age. Neurobiol Aging 26: 973-980.

Giacobini E (1992). Nicotine acetylcholine receptors in human cortex: aging and Alzheimer's disease. In: Lippiello PM, Collins AC, Gray AC, Robinson JH (eds). Biology of Nicotine. Raven: New York, pp 183-215.

Gotti C, Zoli M, Clementi F (2006). Brain nicotinic acetylcholine receptors: native subtypes and their relevance. Trends Pharmacol Sci 27: 482-491.

Hernandez CM, Gearhart DA, Parikh V, Hohnadel EJ, Davis LW, Middlemore ML et al (2006). Comparison of galantamine and donepezil for effects on nerve growth factor, cholinergic markers, and memory performance in aged rats. J Pharmacol Exp Ther 316: 679-694.

Jaarsma D, Ruigrok TJ, Caffe R, Cozzari C, Levey AI, Mugnaini E et al (1997). Cholinergic innervation and receptors in the cerebellum. Prog Brain Res 114: 67-96.

Kume T, Sugimoto M, Takada Y, Yamaguchi T, Yonezawa A, Katsuki $\mathrm{H}$ et al (2005). Up-regulation of nicotinic acetylcholine receptors by central-type acetylcholinesterase inhibitors in rat cortical neurons. Eur J Pharmacol 527: 77-85.

Nordberg A, Winblad B (1986). Brain nicotinic and muscarinic receptors in normal aging and dementia. In: Fisher A, Hanin I, Lachman C (eds). Alzheimer's and Parkinson's Diseases: Strategies for Research and Development. Plenum: New York, pp 95-108.

Papke RL, Porter Papke JK, Rose GM (2004). Activity of alpha7selective agonists at nicotinic and serotonin 5HT3 receptors expressed in Xenopus oocytes. Bioorg Med Chem Lett 14: 1849-1853.

Popa RV, Pierra EF, Lopes C, Maelicke A, Albuquerque EX (2006). The $N$-butylcarbamate derivative of galantamine acts as an allosteric potentiating ligand on alpha7 nicotinic receptors in hippocampal neurons: clinical implications for treatment in Alzheimer's disease. J Mol Neurosci 30: 227-232.

Powell DA, Maxwell B, Penney J (1996). Neuronal activity in the medial prefrontal cortex during Pavlovian eyeblink and nictitating membrane conditioning. J Neurosci 16: 6296-6306.

Power JM, Wu WW, Sametsky E, Oh MM, Disterhoft JF (2002). Age-related enhancement of the slow outward calcium-activated potassium current in hippocampal CA1 pyramidal neurons in vitro. J Neurosci 22: 7234-7243.

Ridley DL, Rogers A, Wonnacott S (2001). Differential effects of chronic drug treatment on alpha $3^{*}$ and alpha7 nicotinic receptor binding sites, in hippocampal neurones and SH-SY5Y cells. $\mathrm{Br} \mathrm{J}$ Pharmacol 133: 1286-1295.

Rogers SW, Gahring LC, Collins AC, Marks M (1998). Age-related changes in neuronal nicotinic acetylcholine receptor subunit $\alpha 4$ expression are modified by long-term nicotine administration. J Neurosci 18: 4825-4832.

Schoepfer R, Conroy W, Whiting P, Gore M, Lindstrom J (1990). Brain $\alpha$-bungarotoxin binding protein cDNAs and mAbs reveal subtypes of this branch of the ligand-gated ion channel gene superfamily. Neuron 5: 35-48.
Simon B, Knuckley B, Curchwell J, Powell DA (2005). Post-training lesions of the medial prefrontal cortex interfere with subsequent performance of trace eyeblink conditioning. J Neurosci 25: 10740-10746.

Simon BB, Knuckley B, Powell DA (2004). Galantamine facilitates acquisition of a trace-conditioned eyeblink response in healthy, young rabbits. Learn Mem 11: 116-122.

Solomon PR, Levine E, Bein T, Pendlebury WW (1991). Disruption of classical conditioning in patients with Alzheimer's disease. Neurobiol Aging 12: 283-287.

Takehara-Nishiuchi K, Nakao K, Kawahara S, Matsuki N, Kirino Y (2006). Systems consolidation requires postlearning activation of NMDA receptors in the medial prefrontal cortex in trace eyeblink conditioning. J Neurosci 26: 5049-5058.

Thompson RF (2005). In search of memory traces. Ann Rev Psychol 56: 1-23.

Wagster MV, Whitehouse PJ, Walker LC, Kellar KJ, Price DL (1990). Laminar organization and age-related loss of cholinergic receptors in temporal neocortex of rhesus monkey. J Neurosci 10: $2879-2885$.

Weible AP, McEchron MD, Disterhoft JF (2000). Cortical involvement in acquisition and extinction of trace eyeblink conditioning. Behav Neurosci 114: 1058-1067.

Weible AP, Oh MM, Lee G, Disterhoft JF (2004). Galantamine facilitates acquisition of hippocampus-dependent trace eyeblink conditioning in aged rabbits. Learn Mem 11: 108-115.

Weible AP, Weiss C, Disterhoft JF (2007). Connections of the caudal anterior cingulate cortex in rabbit: neural circuitry participating in the acquisition of trace eyeblink conditioning. Neuroscience 145: 288-302.

Whiting P, Lindstrom J (1986). Pharmacological properties of immuno-isolated neuronal nicotinic receptors. J Neurosci 6: 3061-3069.

Wickramaratna JC, Fry BG Loiacono RE, Aguilar MI, Alewood PF, Hodgson WC (2004). Isolation and characterization at cholinergic nicotinic receptors of a neurotoxin from the venom of the Acanthophis sp. Seram death adder. Biochem Pharmacol 68 : 383-394.

Woodruff-Pak DS (2006). Stereological estimation of Purkinje neuron number in $\mathrm{C} 57 \mathrm{BL} / 6$ mice and its relation to associative learning. Neuroscience 141: 233-243.

Woodruff-Pak DS, Finkbiner RG, Sasse DK (1990). Eyeblink conditioning discriminates Alzheimer's patients from nondemented aged. NeuroReport 1: 45-48.

Woodruff-Pak DS, Li YT, Kem WR (1994). A nicotinic agonist (GTS-21), eyeblink classical conditioning, and nicotinic receptor binding in rabbit brain. Brain Res 645: 309-317.

Woodruff-Pak DS, Santos IS (2000). Nicotinic modulation in an animal model of a form of associative learning impaired in Alzheimer's disease. Behav Brain Res 113: 11-19.

Woodruff-Pak DS, Vogel III RW, Wenk GL (2001). Galantamine: Effect on nicotinic receptor binding, acetylcholinesterase inhibition, and learning. Proc Natl Acad Sci USA 98: 2089-2094.

Woodruff-Pak DS, Vogel III RW, Wenk GL (2003). Mecamylamine interactions with galantamine and donepezil: effects on learning, acetylcholinesterase, and nicotinic acetylcholine receptors. Neuroscience 117: 439-447.

Zhang X, Wahlstrom G, Nordberg A (1990). Influence of development and aging on nicotinic receptor subtypes in rodent brain. Int J Dev Neurosci 8: 715-721. 